$\xi=2$ 줄

\title{
The effectiveness of platelet concentrations in periodontal surgeries
}

\author{
Ronad Al-Azem ${ }^{1}$, Neveen Ali ${ }^{1}$, Diana Mostafa ${ }^{1,2 *}$ \\ ${ }^{I}$ Preventive Dental Sciences, Al-Farabi College, Riyadh, KSA ${ }^{2}$ Periodontology and Oral Medicine Department. \\ Alexandria University, faculty of Dentistry, Egypt. \\ *Corresponding author E-mail: dr.dianamostafa@gmail.com
}

\begin{abstract}
Platelets release several growth factors which stimulate tissue regeneration. Several techniques for platelet concentrates such as platelet rich plasma (PRP), plasma rich in growth factors (PRGF), platelet rich fibrin (PRF) and concentrated growth factors (CGF) have been introduced in dental surgeries for the prevention of hemorrhage and acceleration of tissue regeneration. However, a fabricating growth factors-enriched bone graft matrix which is called "sticky bone" has been demonstrated to provide stabilization in bony defects. In this article, we presented the method of preparing and utilizing CGF and sticky bone and evaluate the effect of CGF mixed with bone graft and CGF barrier membrane in periodontal surgeries.

Methodology: We used websites such as PubMed, Scopus, and ISI Web of knowledge to get related articles about this subject. The research process involved specific key words " concentrated growth factor"- "Platelet rich fibrin"- growth factors-enriched bone graft" - "sticky bone" to find more articles which published from 2007 to March 2018.

Results: We reviewed 48 articles, 43 articles were excluded. Only five articles have been conducted. Original human studies and case report were included.
\end{abstract}

Conclusion: We concluded that the use of sticky bone and CGF is effective in bone grafting and implant.

Keywords: Concentrated Growth Factors; Platelet Rich Fibrin; Ridge Augmentation; Growth Factors-Enriched Bone Graft; Sticky Bone. Guided Bone Regeneration

\section{Introduction}

Blood is a highly specialized tissue composed of more than 4,000 different kinds of components that presents $7-8 \%$ of human body weight. The most important blood components are red cells, white cells, platelets, and plasma. Platelets are only about $20 \%$ of the diameter of red blood cells, which are produced from large bone marrow cells (megakaryocytes), their normal count is 150,000- 350,000 $/ \mathrm{ml}$ blood. Although, their principal function is to prevent bleeding, they contain high quantity growth factors that stimulate tissue regeneration such as transforming growth factors B-1 (TGFß-1), platelet-derived growth factor (PDGF), epithelial growth factor (EGF), insulin growth factor-I (IFG-I) and vascular endothelial growth factors (VEGF), which stimulates cell proliferation and up regulates angiogenesis [1]. So, platelet aggregate has been widely used to accelerate tissue regeneration and repair in the dental surgeries. The platelet concentrates (PC) have been established in varies techniques including platelet rich plasma (PRP) and plasma rich in growth factors (PRGF) which belong to the first generation of $\mathrm{PC}$, but they require chemical additives such as anticoagulants and thrombin or calcium chloride to induce fibrin polymerization before applying to the surgical site. Platelet rich fibrin (PRF) and concentrated growth factors (CGF) have been introduced as a second generation of PC that utilize patient's venous blood alone to trigger platelet activation and fibrin polymerization [1].

CGF is a fibrin tissue adhesive with hemostatic and tissue sealing properties. It promotes wound healing and stability, and accelerates osteogenesis, which are essential for the establishment of a new connective tissue attachment to a root surface. It also provides a scaffold supporting cytokine attachment and cellular migration. It is an effective surgical hemostatic agent, promotes epithelial, endothelial and epidermal regeneration and decreases dermal scarring. Possess antimicrobial effect due to high concentration of leukocytes. It has anti-angiogenic property on chronic non-healing wound [2]. A new concept of fabricating growth factors-enriched bone graft matrix (also known as "sticky bone") using autologous fibrin glue has been demonstrated since 2010. Sticky bone provides stabilization of bone graft in the defect, and therefore, accelerates tissue healing and minimizes bone loss during the healing period. Fibrin Sealant, or fibrin "glue," is a unique human-derived tissue adhesive that is composed of fibrinogen and coagulation factor XIII and varying amounts of other plasma proteins such as fibronectin and plasminogen. Fibrinogen is a protein that plays a key role in blood clotting. The second component contains thrombin/ Calcium Chloride. Thrombin is an enzyme that helps convert fibrinogen to fibrin. When mixed together, these agents mimic the last stages of the clotting cascade to form a fibrin clot. Autologous Fibrin Glue (AFG) is a biologic product that is produced through centrifugation of the patient's own blood and mixed with thrombin and calcium chloride for its hemostatic and adhesive effects. Its surgical Benefits include reduced bleeding and scarring, minimize serous fluid collection, effective tissue adherence, improved healing and decreased pain [1]. 


\subsection{History and revolution of platelet concentration}

In 1954, Kingsley [3] was the first one who used the term PRP during experiments related to blood coagulation. Then, the regenerative potential of platelets was introduced as "Fibrin glue" by Matras in 1970 [4]. Initially, Platelet rich fibrin was established in France by Choukroun et al [5] in 2000, based on the strong fibrin gel polymerization present in this preparation. It was known as a "second-generation" platelet concentrate because it was significantly dissimilar from other PRPs. In 2006, Sacco used a special centrifuge called Medifuge to prepare a new connotation of concentrated growth factors (CGF), which is similar to PRF, but with a different centrifugation speed, this centrifuge allowed the splitting of a fibrin matrix which is much richer in growth factors [6]. Later, CGF has been shown to have a greater versatility and better regenerative capacity [7].

The first classification of platelet concentrates was proposed by Dohan et al [8], which represented 4 main families based on separation of the products using 2 key parameters: The cellular content (primarily leukocytes) and the fibrin architecture: (1) Pure platelet-rich plasma (P-PRP) - or leukocyte-poor platelet-rich plasma (LP-PRP); (2) Leukocyte-and platelet-rich plasma (L-PRP); (3) Pure PRF (PPRF) - or leukocyte-poor PRF; and (4) Leukocyte- and platelet-rich fibrin (L-PRF).

However, the concept of sticky bone (autologous fibrin glue mixed with bone graft) was introduced by Sohn et al [9] in 2009. While in 2012, Mishra et al [10] established another classification which was restricted to PRP, they stated 4 types of PRP based on the presence or absence of leukocytes and whether the PRP is activated or not and all types can fall into 2 sub-types: A: Platelets $>5 \times$ baseline or B: Platelets $<5 \times$ baseline. In all the following types "solution" means non-activated PRP and gel means activated PRP. Type 1: LPRP solution; Type 2: L-PRP gel; Type 3: P-PRP solution; Type 4: P-PRP gel. At about the same time, DeLong et al [11] conducted another classification called PAW (Platelets quantity, Activation mode, White cells presence) but it was similar to classification by Mishra et al [10] as it was limited to PRP families only.

In 2013, Tunali et al [12] introduced a new product called T-PRF (Titanium-prepared PRF in which titanium tubes were used for centrifugation instead of glass tubes, this was suggested on bases that titanium may activate platelets efficiently more than silica to prepare L-PRF in very thick form. Later, Mourão et al [13] prepared an injectable i-PRF form, where a short centrifuge for $2 \mathrm{~min}$ at 3300 rpm gave an orange color fluid, which can be injected or mixed with bone graft to give a sticky form that can be easily handled inside the bone defect.

\subsection{The preparation of platelets concentrates}

\subsubsection{Preparation of sticky bone}

For preparation of sticky bone, CGF membrane and autologous fibrin glue (AFG) should be prepared at the same time. A 20-60CC of patient's venous blood should be taken from patients' vein in patient's forearm, and the blood is divided into 1-2 non-coated vacutainers (yellow cap to obtain autologous fibrin glue (AFG), which will make sticky bone and 2-7 glass coated test tubes without anticoagulants to obtain CGF layer. The blood in the test tubes should be centrifuged at 2400-2700 rpm using specific centrifuge with a rotor turning at alternated and controlled speed for 12 minutes. The centrifugation time for AFG varies from 2-12 tubes out of the centrifuge. First, the non-coated tube will show different layers. The upper layer is autologous fibrin glue (AFG) layer and red blood cell will be collected in bottom layer which will be discarded. The upper AFG will be obtained with a syringe and mixed with particulate bone powder and allows for 5-10 minutes for polymerization in order to produce sticky bone which is yellow colored. The vacant slot is filled with water filled test tube for weight balance and continued centrifugation to prepare CGF [1].

\subsubsection{Preparation of concentrated growth factor (CGF)}

CGF is an autologous preparation taken from venous blood collected in sterile Vacuette tubes without anticoagulant solutions. The tubes are centrifuged with one step centrifugation protocol: $30 \mathrm{sec}-$ acceleration, $2 \mathrm{~min}-2700 \mathrm{rpm}$, $4 \mathrm{~min}-2400 \mathrm{rpm}$, $4 \mathrm{~min}-2700 \mathrm{rpm}$, $3 \mathrm{~min}-3000 \mathrm{rpm}, 36 \mathrm{sec}$ - deceleration and stop.

This results in [4] different phases which are as follow:

1) Superior phase - Serum

2) Interim phase - Fibrin buffy coat

3) Liquid phase - Growth factors

4) Lower phase - Red blood cells

Phase 1: Superior phase is represented by Serum. It is a clear strawcolored fluid which is the lightest and most liquid part of blood. It contains $92 \%$ of water and $7 \%$ of other concentrates which includes proteins, glucides, amino acids, lipids, enzymes, hormones and inorganic electrolytes. It is used to seal the bleeding capillaries, wash the surgical site, coat and protect the regenerated portions.

Phase 2: Interim phase is a fibrin buffy coat with polymerised fibrin block containing 3-dimensional polymer networks of fibrinogen molecules with interwoven fibers united to form a single phase in the form of gel.

Phase 3: Liquid phase contains growth factors, white blood cells and stem cells. These stem cells are able to differentiate into their specialized cell types. This liquid phase is mixed with autologous bone graft to get high performance activated graft.

Phase 4: This lower phase is a dark reddish dense gel. It consists of a high concentration of red blood cells and also few white cells, platelets and clotting factors. It is used in pure form or mixed with bone grafts to fill large cavities. CGF is taken in a test tube and placed in the metal storage box and compress with metal cover to convert to CGF membrane.

For acceleration of polymerization of AFG, an exudate is taken in the bottom of the metal storage box after compression of CGF layer is added when AFG and the particulate bone graft is mixed. The exudate contains growth factors and autologous thrombin in RBC layer, therefore auto-polymerization will be completed very rapidly. The sticky bone mixed with autologous thrombin in RBC layer shows red in color [2].

\subsection{Advantages of CGF, PRF and sticky bone}

The autologous CGF demonstrates a significant stimulation and acceleration of the healing and formation of the soft tissues and bone. The efficacy of this therapy lies in the local delivery of a wide range and high concentration of growth factors and proteins, taking the practice of regenerative techniques to a sophisticated higher level [14].

Various in vitro studies [14-15] have established the positive effect of PRP on gingival fibroblasts and oral osteoblasts, making it a perfect candidate to promote the periodontal regeneration. In addition, PRP may benefit the healing of surgical sites in fighting postoperative infections via its antibacterial properties against oral pathogenic microorganism such as Staphylococcus Aureus, Streptococcus Agalactiae, Escherichia Coli, Klebsiella Pneumonia and Candida Albicans [15].

Their use during bone grafting procedures, offers varies advantages, as the PRF offers an effective mechanical support in the protection of the bone graft and serves as a biological connector between bone particles. Also, it promotes cellular migration, particularly for endothelial cells, which are necessary for the neoangiogenesis, vascularization and graft survival. In addition, the leukocytes and cytokines (PDGF, TGF-beta, IGF-1) in platelets play a role in the selfregulation of inflammatory, infectious and healing processes within the grafted material [16].

The sticky bone is moldable and well adapted over various shapes of bony defect, which facilitates filling bone to maintain the volume of bone augmentation and prevent the micro and macro-movement of the grafted material during the healing period, which in turn placing a block bone or titanium mesh is not required. Fibrin network entraps platelets and leukocytes to release growth factors, so bone 
regeneration and soft tissue regeneration is accelerated [14]. However, the use of bone graft combined with fibrin, platelets and leukocytes have shown a better histological evidences of bone regeneration by its high osteoblastic activity and maturation than the use of PRF as sole filling material for ridge preservation after extraction. It is a simple, easily prepared procedure, a cost-effective source of growth factors [15].

According to Rodella et al [17] who stated that CGF shows higher tensile strength, more growth factors, higher viscosity and higher adhesive strength than PRF. Therefore, surgeons can use CGF as a barrier membrane to accelerate soft tissue healing or be mixed with bone graft to accelerate new bone formation. In addition, CGF doesn't require any chemical or allergenic additives, such as bovine thrombin or anticoagulants. So, they are free from viral transmission disease [17].

Table 1: shows the clinical human studies using Platelets concentrates in clinical periodontal field.

\begin{tabular}{|c|c|c|c|}
\hline $\begin{array}{c}\text { Author } \\
\text { name \& } \\
\text { year }\end{array}$ & $\begin{array}{l}\text { Type of } \\
\text { the study }\end{array}$ & $\begin{array}{c}\text { Type of platelet con- } \\
\text { centrates and proce- } \\
\text { dure }\end{array}$ & Results \\
\hline $\begin{array}{l}\text { Sohn DS } \\
{[9], 2009}\end{array}$ & $\begin{array}{l}\text { Case } \\
\text { study }\end{array}$ & $\begin{array}{l}\text { CGF in intern maxillary } \\
\text { sinus elevation, in- } \\
\text { frabony pocket and for } \\
\text { GBR in an implant } \\
\text { placement surgery }\end{array}$ & $\begin{array}{l}\text { The results } \\
\text { showed well } \\
\text { augmented } \\
\text { ridge and re- } \\
\text { duction in } \\
\text { Pocket depth. }\end{array}$ \\
\hline \multirow[t]{3}{*}{$\begin{array}{l}\text { Sohn DS } \\
{[1], 2015}\end{array}$} & \multirow[t]{3}{*}{$\begin{array}{l}\text { Case } \\
\text { study }\end{array}$} & $\begin{array}{c}\text { Comparison between } \\
\text { CGF membrane and } \\
\text { collagen membrane in a } \\
\text { case of horizontal bone } \\
\text { defects }\end{array}$ & $\begin{array}{c}\text { After 6-month } \\
\text { of healing pe- } \\
\text { riod, a favora- } \\
\text { ble ridge aug- } \\
\text { mentation was } \\
\text { seen at the both } \\
\text { sites }\end{array}$ \\
\hline & & $\begin{array}{l}\text { Comparison between } \\
\text { sticky bone with/with- } \\
\text { out Titanium Mesh for a } \\
\text { ridge augmentation in } \\
\text { implant placement sur- } \\
\text { gery }\end{array}$ & $\begin{array}{c}\text { After } 4 \text { months } \\
\text { of healing, fa- } \\
\text { vorable hori- } \\
\text { zontal ridge } \\
\text { augmentation } \\
\text { was observed } \\
\text { on both sites }\end{array}$ \\
\hline & & $\begin{array}{l}\text { Sticky bone in treatment } \\
\text { labially fenestrated } \\
\text { ridge of implant surgery }\end{array}$ & $\begin{array}{c}\text { stable bone } \\
\text { augmentation }\end{array}$ \\
\hline $\begin{array}{c}\text { Kim J } \\
{[21], 2016}\end{array}$ & $\begin{array}{l}\text { Case } \\
\text { study }\end{array}$ & $\begin{array}{c}\text { Use of CGF and sticky } \\
\text { bone to remove amal- } \\
\text { gam tattoo }\end{array}$ & $\begin{array}{c}\text { amalgam tattoo } \\
\text { completely dis- } \\
\text { appeared. }\end{array}$ \\
\hline $\begin{array}{c}\text { Ayoub } \\
\text { AH } \\
{[27], 2016}\end{array}$ & $\begin{array}{l}\text { Case } \\
\text { study }\end{array}$ & $\begin{array}{l}\text { Ridge preservation us- } \\
\text { ing PRF and MPM }\end{array}$ & $\begin{array}{l}\text { MPM showed } \\
\text { better histologi- } \\
\text { cal evidence of } \\
\text { hard bone for- } \\
\text { mation than } \\
\text { when PRF is } \\
\text { used } \\
\text { as the sole fill- } \\
\text { ing material for } \\
\text { the extraction } \\
\text { socket after } 4 \\
\text { months. }\end{array}$ \\
\hline $\begin{array}{l}\frac{\text { Qiao J et }}{\text { al }} \\
{[28], 2016}\end{array}$ & $\begin{array}{l}\text { Original } \\
\text { compara- } \\
\text { tive study }\end{array}$ & $\begin{array}{l}\text { Concentrated growth } \\
\text { factors on the treatment } \\
\text { of degree II furcation in- } \\
\text { volvements. }\end{array}$ & $\begin{array}{l}\text { Positive results } \\
\text { of CGFs have } \\
\text { been shown }\end{array}$ \\
\hline
\end{tabular}

Earlier, it was reported that PRF had more advantages than over PRP [16] including; the absence of biochemical handling of blood, the simplicity, cost effectiveness, favorable healing due to low polymerization, more cell migration and proliferation, and minimized blood manipulation. In addition, it does not require the external thrombin because polymerization is a completely natural process, without any risk of suffering from an immunological reaction. Depending on the purpose, it can be used solely or in combination with bone graft which in turn increases the healing rate of bone graft. However, it is presented as more efficient and with fewer controversies on its final clinical results when compared to PRP [15].

\subsection{Disadvantages}

Since knowledge on this topic is still in its preliminary stage, there are no reports of any disadvantages of platelets concentrates in the surgical regenerative procedures.

\subsection{Application of platelets concentrates in clinical peri- odontics}

PRF is a powerful healing biomaterial with inherent regenerative capacity and can be used in various surgical procedures such as intra-bony defects, furcation involvements, sinus lifting, vertical/horizontal ridge augmentations, ridge preservation (socket preservation) and peri-implant defects [18]. PRF can not only be used as a substitute for grafting to elevate the maxillary sinus but it can also provide protection for the sinus membrane during the use of an osteotome, even in case of sinus membrane perforation, the fibrin matrix can aid in wound closure. In addition, it was reported that CGF has the ability to accelerate healing and reduce healing time with gaining bone in sinus lifting procedures. Also, it can be used in ridge augmentation, socket preservation, osseous and furcation defects, peri-implantitis defects, soft tissue grafts and periodontal endodontic lesions. Furthermore, AFG has tissue adhesiveness, glue and elastic properties which increases its importance as an adjunct modality in surgical procedures such as face lifting and endoscopic brow lift procedures to reduce the recovery time, swelling, bruising, discomfort and scar formation [16-17].

\section{Methods}

A literature search of the following electronic databases: MEDLINE/ PubMed, Scopus, and ISI Web of knowledge, was performed to get related articles about this subject. The research process involved specific key words " concentrated growth factor"- "Platelet rich fibrin"- growth factors-enriched bone graft" - "sticky bone" to find more articles about the subject. We were more concerned about English published articles only. Also, all human prospective studies, as well as clinical trials, case-control, and case series studies of uses of platelets concentrates in clinical dental surgeries were evaluated, which was published from 2007 to March 2018. Articles on experimental and animal studies were not evaluated, also, letters, editorials and reviews were excluded. The titles and abstracts of potential references were manually examined to exclude irrelevant publications and the full texts of the relevant papers were then reviewed. Authors, years of publication, type of platelet concentrates, results were extracted from the selected studies. The study targeted the use of platelets concentrates especially CGF and sticky bone in periodontal surgeries.

\section{Results}

Our initial search strategy yielded 48 articles potentially relevant publications. We excluded 43 articles because they were either unrelated to our subject or not based on the inclusion criteria. After full text evaluation, [5] studies were included in this review (Figure 1). Original studying articles and case reports were investigated by the authors and processed for data extraction. The studies included one original comparative research study and four case studies, most of the studies presented positive clinical outcomes in follow-up periods as shown in table 1 . 


\section{Discussion}

PRP as platelet aggregates was first introduced in the dental field by Marx et al. [19] as PRP has been used in sinus augmentation, ridge augmentation, periodontal regeneration and soft tissue healing. Since, the technique of PRP and PRGF extract platelet concentrates has the possibility of procedural errors and only $10 \%$ of acquired blood is used which is considered as a waste of patient's blood, PRF and CGF overcome this disadvantage of PRP and PRGF. However, CGF is known to have higher tensile strength, more growth factors and further viscosity than PRF, so compressed CGF can be used as a barrier membrane with growth factors which is considered as alternative collagen membrane. [20-21]

In 2009, Sohn [22] used CGF for intern sinus elevation and guided bone regeneration (GBR) for implant replacement where he used Hydrodynamic piezoelectric to elevate the sinus membrane, then one piece of CGF was inserted under the elevated sinus membrane, Implant was placed and bovine bone was grafted to augment vertical and horizontal defect around implant. After that, CGF barrier was covered on the graft to accelerate new bone formation and exclude soft tissue in growth. The result of this case showed well augmented ridge even though the healing period was not enough. In another case, he used Allograft mixed with CGF to graft in the infra-bony pocket and CGF barrier was cover the on the graft to accelerate new bone regeneration and soft tissue healing. Pocket depth was diminished after 5 months healing and bone regeneration was observed in the radiogram. Furthermore, he reported the beneficial use of CGF for GBR in an implant surgery, he obtained pieces of CGF where they were transformed to CGHF barrier membrane while some were mixed with mineral allograft to accelerate bone formation and to a make gel conditioned bone graft. After only 12 weeks, excellent bone regeneration was gained.

In 2015, the same author [1] made a study which compared between CGF membrane and collagen membrane in a case of horizontal bone defects, seeking for implant supported fixed restoration. The procedure was done using mineral allograft mixed with exudates taken from compressed CGF and grafted on horizontal bony defect and a collagen membrane, after 6 months of the healing period, a favorable ridge augmentation was seen at the both sites. Both histological specimens revealed favorable new bone formation along mineral allograft without sign of inflammation. In another case, he compared sticky bone with/without Titanium Mesh for a ridge augmentation and implant placement. He prepared sticky bone using bovine bone and mineral allograft and used a resorbable collagen membrane at the bony defect sites, then, a particulate bone graft was placed on other defect and titanium mesh was covered to stabilize the particulate bone graft, three CGF membrane was covered over the bone graft and mesh. After 4 months of healing, favorable horizontal ridge, augmentation was observed at both sites. This is because sticky bone did not migrate during healing period, while in another case; he planned to place 3 immediate implants in labial fenestrated ridge using sticky bone and tunnel technique for horizontal ridge augmentation as minimally invasive technique. After 1 year of loading, the cross-sectional image of cone beam computed tomogram shows stable bone augmentation.

In addition, Kim [21] reported in 2015 that Utilization of Autologous Concentrated Growth Factors (CGF) Enriched Bone Graft Matrix (Sticky Bone) and CGF-Enriched Fibrin Membrane is very effective in implant dentistry. CGF with changeable centrifugation speed from 2,400-2,700 rpm gave much larger, denser and richer in growth factors enriched fibrin matrix. As an alternative to bone substitutes, growth factors enriched fibrin gel revealed active new bone formation in the maxillary sinus without complication of postoperative infection [18-20].

Since atrophic alveolar ridge considered being a challenge for implant replacement, guided bone regeneration (GBR) using bone graft and barrier membrane is a well-established technique for augmentation of atrophic alveolar ridges [23-24]. However, for successful GBR, stability of bone graft, space maintenance, angiogenesis, and tension free primary suture are essential. PRF and CGF in

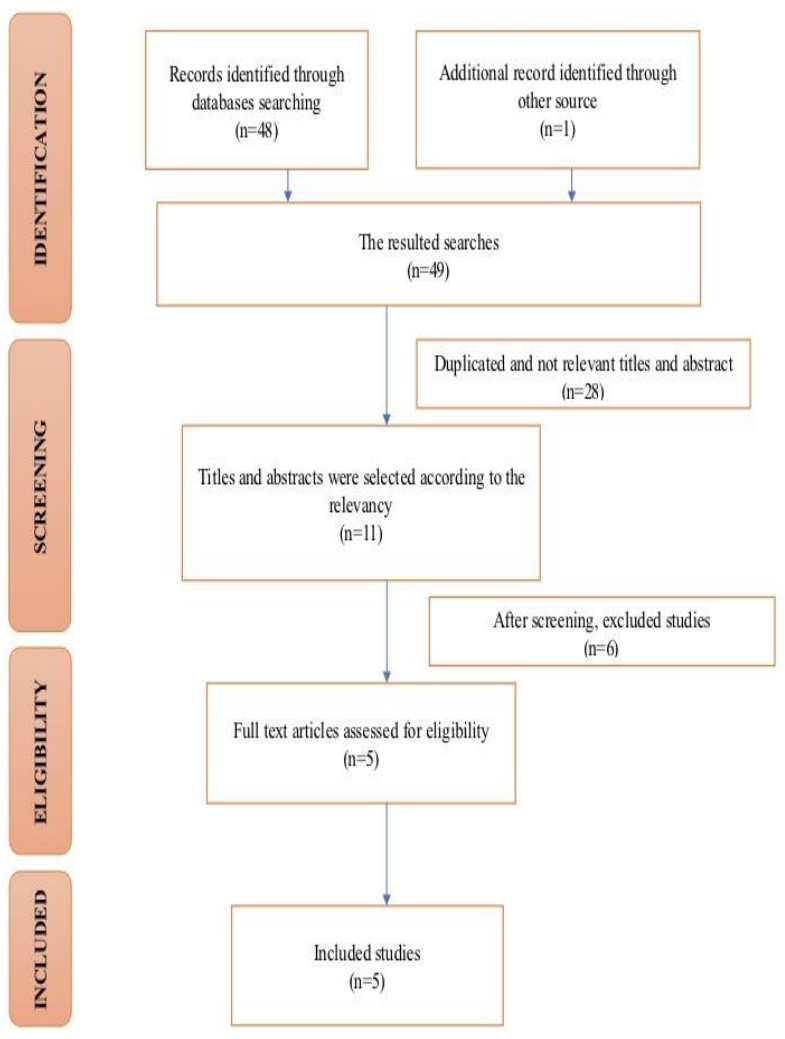

Figure 1: Article selection flow chart for screening process

a compressed membrane-like form has also been used as a substitute for commercially available collagen barrier membranes in these cases to improve tissue healing [21-24]. Also, it was reported that CGF is used as a membrane support to accelerate bone integration during implant placement [1].

In addition, the sticky bone was introduced as a replacement of the bone graft material in 2010. It is solidified bone graft which does not scatter even upon being shaken with cotton pliers because particulate bone powders are strongly interconnected with each other by a fibrin network [25]. It has moldable character which makes it well and easily adaptable over varies types of bone defects with no micro and macro movement of grafted bone. So, the volume of augmentation is maintained during the healing period, therefore the need of block bone and titanium mesh is minimized. Also, fibrin network entraps platelets and leukocytes to release growth factors which increase bone formation and accelerate healing of tissues. Unlike PRP and PRGF, no biochemical additives are needed to make sticky bone [26].

Kim [21] presented a case for old female who has fractured endodontically treated upper central incisors and wanted to remove the amalgam tattoo caused by the previous apical surgery. He extracted the tooth and placed an immediate implant, the remaining soft and hard tissue defect, including the vestibular area with amalgam tattooed soft tissue was excised widely. This area was grafted with "sticky bone" and CGF. After 6 months healing period, amalgam tattoo was completely disappeared and full coverage restoration was fabricated and delivered in 12-months post-surgery.

However, there was a different case of ridge preservation which was reported by Ayoub [27] in 2016, a mineralized plasmatic matrix (MPM) placed in the extraction socket of the lateral incisor \#41 and in a socket of canine, he placed PRF membrane. After 4 months, he raised a flap and bone harvested and sent to a laboratory for histological evaluation. The result of his study reveals that the MPM 
specimen presented with a mass of cancellous bone with areas of diverse degree of maturation, this is because osteoblastic activity of the specimen is more prominent and active, resulting in the deposition of woven bone while the PRF specimen presented with a less osteoblastic activity, resulting in a fibrotic bone marrow with little vascularity.

Also, we reviewed a study that was reported in 2016 by Qiao et al [28], who showed the effect of concentrated growth factors on the treatment of grade II furcation involvements in comparative study, where the subjects were randomly divided into two groups; the furcation involvements in the experimental group were treated with bone graft therapy combined with CGFs, and the furcation involvements in the control group were treated with bone graft therapy alone. The changes of clinical and CBCT data at baseline and 1 year post-surgery were compared between the two groups and results showed positive role of CGF in the treatment of grade II furcation involvements other than the control group.

Furthermore, Kshirsagar [2] stated that CGF has a wide range of healing property in patients undergoing cosmetic surgeries like facelifts, neck lifts maxillofacial surgeries. It can act as a membrane support in recession and root coverage as it is constantly release growth factors to produce tissue regeneration [25].

\section{Conclusion}

Based on the results of the study, CGF membrane and sticky bone are easy to make and they are very effective materials for the reconstruction of edentulous alveolar defects, sinus elevation, dimension pocket depth, treatment of furcation involvements, socket preservation and guided bone regeneration. Although, reports on the use of platelets concentrates in periodontal surgeries are published, quality literature is scarce. Most of the published researches are case reports of series while randomized clinical trials are rare. More histological and clinical studies with larger samples and long duration of follow up periods are needed to confirm these results.

\section{References}

[1] Sohn DS..Utilization of Autologous Concentrated Growth Factors (CGF) Enriched Bone Graft Matrix (Sticky Bone) and CGF-Enriched Fibrin Membrane in Implant Dentistry. The Journal of Implant \& Advanced Clinical Dentistry.2015; 7:10:11-29.

[2] Kshirsagar JT, Innovation in regeneration - Concentrated growth factor, International Journal of Applied Dental Sciences 2017; 3(2): 206-208.

[3] Kingsley CS. Blood coagulation; evidence of an antagonist to factor VI in platelet-rich human plasma. Nature. 1954; 173:723-724. https://doi.org/10.1038/173723a0.

[4] Matras H. [Effect of various fibrin preparations on reimplantations in the rat skin] Osterr Z Stomatol. 1970; 67:338-359.

[5] Choukroun J, Adda F, Schoeffer C, Vervelle A. PRF: An opportunity in perio implantology. Implantodontie. 2000; 42:55-62.

[6] Bernardi S, Mummolo S, Tecco S, Continenza MA \& Marzo G. Histological characterization of Sacco has concentrated growth factors membrane. Int. J. Morphol.2017, 35(1):114-119. https://doi.org/10.4067/S0717-95022017000100019.

[7] Aghaloo TL, Moy PK. Which hard tissue augmentation techniques are the most successful in furnishing bony support for implant placement? Int J Oral Maxillofac Implants.2007; 22:49-70.

[8] Dohan Ehrenfest DM, Rasmusson L, Albrektsson T. Classification of platelet concentrates: from pure platelet-rich plasma (P-PRP) to leucocyte- and platelet-rich fibrin (L-PRF) Trends Biotechnol 2009 27:158-167. https://doi.org/10.1016/j.tibtech.2008.11.009.

[9] Sohn DS, Moon JW, Moon YS, Park JS, Jung HS. The use of concentrated growth factors (CGF) for sinus augmentation. J Oral Implant. 2009; 38:25-38.

[10] Mishra A, Harmon K, Woodall J, Vieira A. Sports medicine applications of platelet rich plasma. Curr Pharm Biotechnol. 2012; 13:1185-1195. https://doi.org/10.2174/138920112800624283.

[11] DeLong JM, Russell RP, Mazzocca AD. Platelet-rich plasma: the PAW classification system. Arthroscopy. 2012; 28:9981009. https://doi.org/10.1016/j.arthro.2012.04.148.

[12] Tunalı M, Özdemir H, Küçükodacı Z, Akman S, Fıratlı E. In vivo evaluation of titanium-prepared platelet-rich fibrin (T-PRF): a new platelet concentrate. Br J Oral Maxillofac Surg. 2013; 51:438 443. https://doi.org/10.1016/j.bjoms.2012.08.003.

[13] Mourão CF, Valiense H, Melo ER, Mourão NB, Maia MD. Obtention of injectable platelets rich-fibrin (i-PRF) and its polymerization with bone graft: technical note. Rev Col Bras Cir. 2015; 42:421423. https://doi.org/10.1590/0100-69912015006013.

[14] Anitua E, Tejero R, Zalduendo MM, Orive G. Plasma rich in growth factors promotes bone tissue regeneration by stimulating proliferation, migration, and autocrine secretion in primary human osteoblasts. J Periodontol. 2013; 84:1180-1190. https://doi.org/10.1902/jop.2012.120292.

[15] Rosenkranz S, Kazlauskas A. Evidence for distinct signaling properties and biological responses induced by the PDGF receptor alpha and beta subtypes. Growth Factors. 1999 16(3):201-216. https://doi.org/10.3109/08977199909002130.

[16] Anitua E, Alonso R, Girbau C, Aguirre JJ, Muruzabal F, Orive G. Antibacterial effect of plasma rich in growth factors (PRGF ®-Endoret $\left.{ }^{\circledR}\right)$ against Staphylococcus aureus and Staphylococcus epidermidis strains. Clin Exp Dermatol.2012 Aug 37(6):652-7. https://doi.org/10.1111/j.1365-2230.2011.04303.x.

[17] Rodella LF, Favero G, Boninsegna R, et al. Growth factors, CD34 positive cells, and fibrin network analysis in concentrated growth factors fraction. Microsc Res Tech. 201174 (8):772-777. https://doi.org/10.1002/jemt.20968.

[18] Plachokova AS, Nikolidakis D, Mulder J, Jansen JA, Creugers NH. Effect of platelet-rich plasma on bone regeneration in dentistry: a systematic review. Clincal Oral Implants Res. 200819 (6):539-45. https://doi.org/10.1111/j.1600-0501.2008.01525.x.

[19] Marx RE, Carlson ER, Eichstaedt RM, Schimmele SR, and Strauss JE, Georgeff KR. Platelet-rich plasma: Growth factor enhancement for bone grafts. Oral Surg Oral Med Oral Pathol Oral Radiol Endod. 1998;85 (6):638-46 https://doi.org/10.1016/S1079-2104(98)900294.

[20] Upadhayaya V, Arora A, Goyal A. Bioactive Platelet Aggregates: Prp, Prgf, Prf, Cgf And Sticky Bone .JDMS 2017;16(5):5-11

[21] Kim JY, Rehabilitation of A Non-Restorable Maxillary Central Incisor Tooth for Function and Esthetic Utilizing An Immediate Placement and Provisionalization Protocol, Global Dental Implant Academy.2016;1(1):1-4

[22] Sohn DS. Lecture titled with sinus and ridge augmentation with CGF and AFG, Symposium on CGF and AFG. Tokyo, June 6; 2010.

[23] Bozkurt Dog an S, O€ngo€z Dede F, Ballı U, Atalay EN, Durmu slar MC. Concentrated growth factor in the treatment of adjacent multiple gingival recessions: a split mouth randomized clinical trial. J Clin Periodontol. 2015; 42:868-875. https://doi.org/10.1111/jcpe.12444.

[24] Wang HL1, Al-Shammari K. HVC ridge deficiency classification: a therapeutically oriented classification. Int J Periodontics Restorative Dent. 200222 (4):335-343.

[25] Sohn DS, Heo JU, Kwak DH et al. Bone regeneration in the maxillary sinus using an autologous fibrin-rich block with concentrated growth factors alone. Implant Dent.2011; 20(5):389-395. https://doi.org/10.1097/ID.0b013e31822f7a70.

[26] Gupta V., Bains B.K., Singh G.P., Mathur A., Bains R. Regenerative potential of platelet rich fibrin in dentistry: literature review. Asian. J. Oral. Health. Allied. Sci. 2011; 1:22-28.

[27] Ayoub AH, Ramadan OR, Agbor MA. Tissue Engineering, Platelets Concentrates and it's Role in Dental Implant Treatment. EC Dental Science 2016; 5(1):969-980.

[28] Qiao J, Duan J, Zhang Y, Chu Y, Sun C. The effect of concentrated growth factors in the treatment of periodontal intrabony defects. Future Science OA.2016 2 (4):FS136. 